\title{
Modeling and Control of Turbocharged SI and DI Engines
}

\author{
L. Eriksson \\ Vehicular Systems, Dept. of Electrical Engineering \\ Linköping University, SE-58183 Linköping - Sweden \\ e-mail: larer@isy.liu.se
}

\begin{abstract}
Résumé - Modélisation et contrôle de moteurs suralimentés à allumage commandé et à injection directe - Une méthodologie pour la modélisation par composants de moteurs suralimentés est décrite et appliquée. Plusieurs modèles à composants sont considérés et évalués. De plus, de nouveaux modèles sont élaborés incluant l'efficacité du compresseur, le flux dans le compresseur, et le flux dans la turbine. Enfin, deux exemples d'application qui utilisent cette méthodologie et ces modèles de composants sont présentés. Les applications sont, d'une part, la conception d'observateurs et le contrôle du rapport air/carburant de moteurs à allumage commandé, et d'autre part la conception du contrôle de moteurs à injection directe incluant un turbocompresseur à géométrie variable et le recyclage de gaz d'échappement.
\end{abstract}

\begin{abstract}
Modeling and Control of Turbocharged SI and DI Engines - A component based modeling methodology for turbocharged engines is described and applied. Several component models are compiled and reviewed. In addition new models are developed for the compressor efficiency, compressor flow, and turbine flow. Two application examples are finally given where the modeling methodology and the component models have been used. The applications are, firstly, observer design and airlfuel ratio control of SI engines and, secondly, control design of DI engines with VGT and EGR.
\end{abstract}




\section{INTRODUCTION}

Environmental concern coupled to pollutants and consumption of our finite resources is driving the technological development of engines and vehicles. Higher demands from legislators and customers are met by introducing new technological solutions that give the system designer more degrees of freedom to utilize when optimizing a vehicles performance. One interesting path for improving the fuel efficiency is to downsize and supercharge the engines [1-3]. These new systems combined with the already complex engines require proper control and gives the controls engineer a more complex task to handle. One way to handle the complexity is to utilize model-based methods where the components and the complex interactions between them are described by models. These models are utilized in a central way in the design of the control and supervision systems.

Mean Value Engine Models (MVEM) have a complexity that is favorable for design of control and supervision systems, where they form an excellent basis for $e . g$. control and observer design. Consequently have they been successfully utilized in several aspects of engine management [4-6] and engine supervision [7,8]. These MVEM are usually formulated as a non-linear Ordinary Differential Equation (ODE) which gives a model complexity suitable for control design, as opposed to wave action models based on partial differential equations that are used for more detailed (and computationally expensive) modeling.

A modeling methodology for MVEM, based on a component view, was outlined in [9] and applied to a turbo charged spark ignited (SI) engine. This methodology, that focuses on the gas flows in the engine, has been refined and successfully applied in several projects. The methodology is based upon a component view of the system and many of the components used are well known and therefore the majority of modeling work in the paper is focused on new insights on component models that describe the compressor and turbine performance. Finally two control applications are described where the modeling methodology has successfully been applied and where the models have been used in a central way in the development of the controller.

\section{MODELING METHODOLOGY}

Efficient reusage of models is important from an industrial perspective, where equations that have been implemented and thoroughly validated can be reused to give leverage in new projects. It is also beneficial if the models also cover a wide variety of engines. Figure 1 shows two turbocharged engines, one gasoline and one diesel, the main difference between them is the absence of throttle in the diesel engine and a Variable Geometry Turbine (VGT) on the diesel engine instead of a wastegate (there are also diesel engines with wastegate and with a throttle on the intake side). As Figure 1 shows many components can be found on both engines and therefore a component based approach to the modeling can facilitate the reusage of the models in a wide variety of projects.

The general modeling methodology applied here is to divide the system into components and then defining boundaries and interactions with the aid of physics and thermodynamics. The components are arranged according to a scheme where control volumes are placed in series with flow governing components such as for example compressor, engine, or restrictions. These flow governing components are here collectively named restrictions. Control volumes have the mass and energy conservation equations and the restrictions determine the transport of mass and energy.

Examples of control volumes are those where mass is collected: intake manifold, exhaust manifold, all the sections of the pipes between components including the inlets and outlets of the upstream and downstream components respectively. Examples of restrictions are: air filter, compressor, intercooler, throttle, engine, turbine, catalyst, exhaust system. To exemplify this methodology the first part of the intake system is realized as follows:

\section{Air filter-pipe-compressor-pipe-intercooler restr - CV - restr - CV - restr}

With this component view on the modeling it is easy to develop and maintain a library with a set of generic components.

\section{COMPONENT MODELS}

With the division into components, given above, the component models have to be developed but there are also design choices with the interfaces. The main equations in the control volumes are mass and energy balances and therefore the natural choice is to have the mass and energy flows given by the restrictions. Furthermore it is also beneficial to base the model equation on measurable quantities, such as mass flow, pressure and temperature, since the models can then easily be tuned and validated. Consequently it is natural to select the pressure and the temperature as state variables for the control volumes and the mass flow and temperature of the flowing fluid as the transported properties in the restrictions.

\subsection{Control Volumes}

For control volumes there two options, either to use a simple mass balance and the ideal gas state equation, or to use both the mass balance and energy balance. With the first approach the differential equation for the pressure $p$ in the control volume then becomes

$$
\frac{d p}{d t}=\frac{R T}{V}\left(W_{\mathrm{i}}-W_{\mathrm{o}}\right)
$$



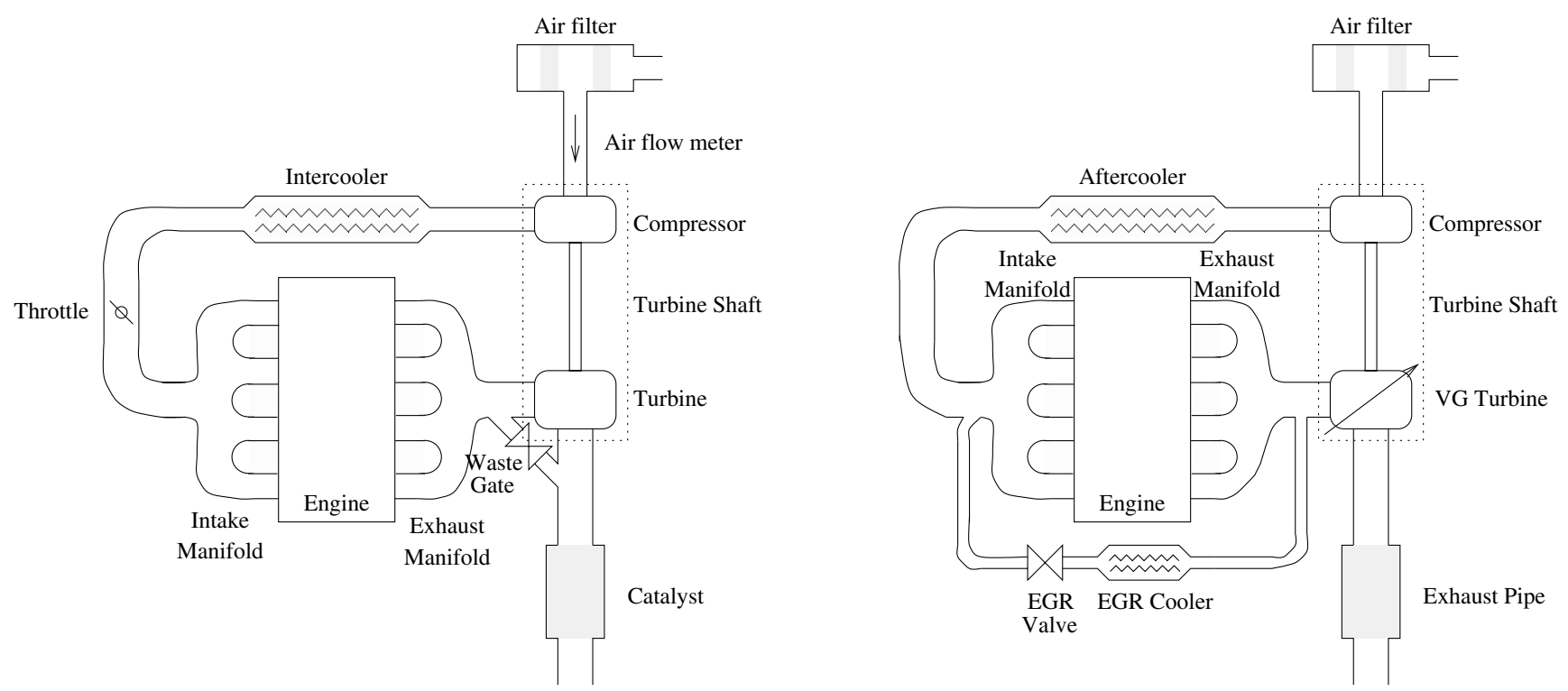

Figure 1

Left: A sketch showing frequently used components in a turbocharged SI engine.

Right: A sketch showing frequently used components in a turbocharged diesel (CI) engine.

where $W$ denotes mass flow. This model violates the energy equation but it gives good agreement with measured pressures and it is simple to implement and tune to dynamic measurement data from engines. The other choice is to use both the energy and mass balance which gives the following differential equations for the pressure and temperature

$$
\begin{aligned}
m & =\frac{p V}{R T} \\
\frac{d T}{d t} & =\frac{1}{m c_{v}}\left[W_{i} c_{v}\left(T_{i}-T\right)+R\left(T_{i} W_{i}-T W_{o}\right)+\dot{Q}\right] \\
\frac{d p}{d t} & =\frac{R T}{V}\left(W_{i}-W_{o}\right)+\frac{m R}{V} \frac{d T}{d t}
\end{aligned}
$$

For a longer discussion about these models and the differences between them see [10].

\subsection{Flow Restrictions}

\subsubsection{Components with Pressure Losses}

Several components that are placed the air path of the engine have pressure losses over them e.g. air filter, intercooler, catalyst, exhaust system, and pipe bends. They are well described by the equation for incompressible and turbulent flow, see for example [11], where the pressure drop has a quadratic dependence on the mass flow, $p_{u s}-p_{d s}=$ $C_{f r} \frac{R T_{u s}}{p_{u s}} \cdot W^{2}$, where $p_{u s}$ is upstream pressure, $p_{d s}$ is downstream pressure, and $T_{u s}$ is upstream temperature. To fit into the modeling framework it is rewritten so that it returns the mass flow $W$ as function of the pressure and temperature

$$
W=\left\{\begin{array}{cc}
\sqrt{\frac{p_{u s}\left(p_{u s}-p_{d s}\right)}{C_{f r} T_{u s}}} & p_{u s}-p_{d s} \geq p_{\text {lin }} \\
\sqrt{\frac{p_{u s}}{C_{f r} T_{u s}}} \frac{p_{u s}-p_{d s}}{\sqrt{p_{l i n}}} \quad \text { otherwise }
\end{array}\right.
$$

Another aspect that is important to take into account is that the function should fulfill the Lipschitz condition to guarantee that there exists a solution to the ODE. Therefore the region close to zero has a linear region around $p_{u s}-p_{d s} \leq p_{\text {lin }}$. This extension is also motivated by the physics since the flow is laminar for low flow velocities and when the flow velocity increases it becomes turbulent and this gives a transition, see [12] for a discussion and another type of a transition. Applications and validations of these component models are found in for example [9, 13].

\subsubsection{Actuator Valves}

Actuator valves are frequently used, for example throttle, EGR-valve, wastegate, and compressor bypass. These have higher pressure losses and flow velocities and require that models for compressible flow through a nozzle are used (see for example Appendix C in [14] for a derivation).

$$
W\left(u, p_{\mathrm{us}}, p_{\mathrm{ds}}, T_{\mathrm{us}}\right)=\frac{p_{\mathrm{us}}}{\sqrt{R T_{\mathrm{a}}}} A_{\mathrm{e}}(u) \Psi\left(\Pi_{\mathrm{th}}\right)
$$




$$
\begin{aligned}
\Psi\left(\Pi_{\mathrm{th}}^{*}\right) & =\sqrt{\frac{2 \gamma}{\gamma-1}\left(\Pi_{\mathrm{th}}^{*} \frac{2}{\gamma}-\Pi_{\mathrm{th}}^{*} \frac{\gamma+1}{\gamma}\right)} \\
\Pi_{\mathrm{th}}^{*} & =\max \left(\frac{p_{\mathrm{ds}}}{p_{\mathrm{us}}},\left(\frac{2}{\gamma+1}\right)^{\frac{\gamma}{\gamma-1}}\right)
\end{aligned}
$$

where $A_{e}(u)$ is the effective area as a function of the control input. This function should also be extended so that it fulfills the Lipschitz condition at $\frac{p_{\mathrm{ds}}}{p_{\mathrm{us}}}=1$ to avoid numerical problems for large control valve openings and for low flows.

\subsection{Engine Air Mass and Temperature}

The air flow into the cylinders of the engine is modeled using the standard model, based on the volumetric efficiency

$$
W_{\mathrm{ac}}=\frac{\eta_{\mathrm{vol}}\left(p_{\mathrm{im}}, N, p_{\mathrm{em}}\right) V_{\mathrm{d}} N}{2 R T_{\mathrm{im}}} p_{\mathrm{im}}
$$

where $\eta_{\mathrm{vol}}\left(p_{\mathrm{im}}, N, p_{\mathrm{em}}\right)$ is either mapped or a parameterized function. Other effects such as charge cooling by fuel evaporation and exhaust back pressure dependence can also be included, see e.g. [15].

\subsubsection{Exhaust Manifold Temperatures}

In naturally aspirated engines the exhaust temperature models are only important if catalyst temperatures are studied. When considering turbo charged engines these temperatures become even more important due to their direct influence on the turbine power and thus the charging of air on the intake side.

In SI engines, that operate at stoichiometric conditions, the temperature out of engine can be modeled as a function of air mass flow $T_{\mathrm{em}}=f\left(W_{\mathrm{ac}}\right)$ [16]. For DI engines more complex models have been used see for example [17].

\subsubsection{Turbine Inlet Temperature}

From the engine to the turbine and to the catalyst energy is lost due to heat transfer. Control oriented models for the exhaust heat transfer have been presented in [16]. See also $[13,17]$ for examples of when these models are applied to different engines.

\subsection{Turbo Performance and Modeling}

To integrate compressors and turbines into the gas-flow modeling framework they are modeled as generalized restrictions that deliver mass flows and temperatures of the flowing gases. Therefore the aim is to develop models that have the following functional representations

$$
\begin{gathered}
W_{c}\left(p_{01}, p_{02}, T_{01}, N_{t c}\right), T_{c}\left(p_{01}, p_{02}, T_{01}, N_{t c}\right) \\
W_{t}\left(p_{03}, p_{04}, T_{03}, N_{t c}\right), T_{t}\left(p_{03}, p_{04}, T_{03}, N_{t c}\right)
\end{gathered}
$$

Furthermore it is also necessary to model the rotational dynamics which is the most dominant dynamics in a turbocharged engine. The turbocharger speed is modeled using Newton's second law for rotating systems with a friction term

$$
\frac{d \omega_{t c}}{d t}=\frac{1}{J_{t c}}\left(\frac{P_{t}}{\omega_{t c}}-\frac{P_{c}}{\omega_{t c}}-M_{\text {fric }}\left(\omega_{t c}\right)\right)
$$

where the turbine power $P_{t}$ drives the compressor $P_{c}$. Modeling of power, flows, and temperatures will be discussed after dimensional numbers have been introduced.

\subsubsection{Dimensional Analysis}

Dimensional analysis gives insight into what effects and dependencies are important for the performance. In particular the measurements and determination of the turbo charger performance rely upon these to reduce the number of necessary measurements and to give a compact description of the performance.

A major benefit of using dimensionless numbers is that they reduce the amount of expensive measurements needed for determining turbocharger performance. A turbochargers performance is determined from measurements taken at several operating points with given inlet pressure, inlet temperature, mass flow, etc. To be able to use the measured performance we want to know how it changes with for example the inlet pressure, covering low and high altitudes, or temperature covering winter and summer driving. Dimensionless numbers give insight into many of these dependencies and reduces the number of necessary measurements. Furthermore, dimensionless numbers are also directly useful when modeling compressors and turbines and they are the basis for the models developed in Sections 3 and 4.

Dimensionless numbers and their usage for determining turbomachinery performance is given in $[18,19]$, and they are summarized below. The three performance parameters: isentropic stagnation enthalpy

$$
\Delta h_{01}=c_{p} T_{01}\left[\left(p_{02} / p_{01}\right)^{(\gamma-1) / \gamma}-1\right]
$$

efficiency $\eta$, and delivered power $P$ have the following functional expressions for a turbomachine that operates with a compressible working fluid

$$
\left[\Delta h_{01}, \eta, P\right]=f\left(D, N, W, \rho_{01}, a_{01}, \mu, \gamma\right)
$$

Here the performance depends upon $D$-diameter, $N-$ rotational speed, $W$-mass flow, $\rho_{01}$-inlet density, $a_{01}$-inlet stagnation speed of sound, $\mu$-dynamic viscosity, $\gamma$-ratio of specific heats. Modeling of the compressor is the task of determining the three functions $f(\ldots)$ above. This task is promoted by the dimensional analysis which reduces the 
dimensions to the following quantities (see e.g. [20])

$$
\begin{gathered}
\Psi=\frac{\Delta h_{0 s}}{N^{2} D^{2}}=f_{1}\left(\frac{W}{\rho_{01} N D^{3}}, \frac{\rho_{01} N D^{2}}{\mu}, \frac{N D}{a_{01}}, \gamma\right) \\
\eta= \\
f_{2}\left(\frac{W}{\rho_{01} N D^{3}}, \frac{\rho_{01} N D^{2}}{\mu}, \frac{N D}{a_{01}}, \gamma\right) \\
\hat{P}=\frac{P}{\rho N^{3} D^{5}}=f_{3}\left(\frac{W}{\rho_{01} N D^{3}}, \frac{\rho_{01} N D^{2}}{\mu}, \frac{N D}{a_{01}}, \gamma\right)
\end{gathered}
$$

where $\operatorname{Re}=\frac{\rho_{01} N D^{2}}{\mu}$ is a form of Reynolds number, $N D / a_{01}$ is called the blade mach number, and

$$
\Phi=\frac{W}{\rho_{01} N D^{3}}
$$

is called the flow coefficient.

\subsubsection{Corrected Quantities}

For an ideal gas the third dimensionless group is substituted into the first, and $\Psi$ is exchanged for pressure ratio. The power parameter is also exchanged for the temperature quotient. With these manipulations the following expressions and variables are used.

$$
\frac{p_{02}}{p_{01}}, \eta, \frac{\Delta T_{0}}{T_{01}}=f\left(\frac{W \sqrt{R T_{01}}}{D^{2} p_{01}}, \frac{N D}{\sqrt{R T_{01}}}, R e, \gamma\right)
$$

The influence of the Reynolds number is usually small, so it is often disregarded. Finally, when the performance is studied for a machine of given size and given fluid then $R, \gamma, D$ remain constant and are therefore left out

$$
\frac{p_{02}}{p_{01}}, \eta, \frac{\Delta T_{0}}{T_{01}}=f\left(\frac{W \sqrt{T_{01}}}{p_{01}}, \frac{N}{\sqrt{T_{01}}}\right)
$$

Note that the independent variables in the last expression are not dimensionless and these quantities are named corrected mass flow and corrected speed

$$
W_{\text {corr }}=\frac{W \sqrt{T_{01}}}{p_{01}}, \quad N_{c o r r}=\frac{N}{\sqrt{T_{01}}}
$$

Compressor and turbine data are represented using maps with either those corrected quantities given above or the following ones that are also called corrected mass flow and corrected speed

$$
W_{\text {corr }}=\frac{W \sqrt{\left(T_{01} / T_{\text {ref }}\right)}}{\left(p_{01} / p_{\text {ref }}\right)}, \quad N_{\text {corr }}=\frac{N}{\sqrt{\left(T_{01} / T_{\text {ref }}\right)}}
$$

where $T_{\text {ref }}$ and $p_{\text {ref }}$ are reference conditions. In the majority of the turbocharger data reported in this paper the last one is most common but both are used. It is thus important to be very careful when interpreting the performance maps that are provided by manufacturer.

\subsubsection{Compressor and Turbine Maps}

A typical compressor map is shown in Figure 2, which is a graphical representation of the measurement data that is provided by the manufacturer. The performance variables $\Pi_{c}=\frac{p_{02}}{p_{01}}$ and $\eta_{c}$ in (11) are described using the corrected quantities in (12). In the map corrected flow $W_{c, \text { corr }}$ is on the $\mathrm{x}$-axis, pressure ratio $\Pi_{c}$ on the $\mathrm{y}$-axis, dotted lines show constant corrected speed $N_{c, c o r r}$, and the color map represent the efficiency $\eta_{c}$.

A turbine map is shown in Figure 3, which shows expansion ratio $1 / \Pi_{t}$, efficiency $\eta_{t}$, and corrected compressor mass flow $W_{t, \text { corr }}$. The purpose of the compressor and turbine modeling is thus to describe the maps shown in Figures 2 and 3 , in such a way that they fit into the general modeling framework and this is the topic in the following two sections.

\section{COMPRESSOR MODELS}

Modeling the compressor performance is challenging since there are many phenomenas that are important to account for. The goal of the modeling is to have a model that can deliver the mass flow $W_{c}$, temperature out of the compressor $T_{02}$, and the power consumption $P_{c}$ of the compressor so that these can be incorporated into (4) and (6). A first law analysis of the compressor gives the expression for the power consumption of the compressor

$$
P_{c}=W_{c} c_{p}\left(T_{02}-T_{01}\right)
$$

where it is assumed that $c_{p}$ is constant during the compression. Now turning to the efficiency which is defined as the smallest power required to compress the gas from $p_{01}$ to $p_{02}$ (which is given by the isentropic process), divided by the actual consumed power we get [18]

$$
\eta_{c}=\frac{P_{c, \text { ideal }}}{P_{c}}=\frac{\left(\frac{p_{02}}{p_{01}}\right)^{\frac{\gamma-1}{\gamma}}-1}{\frac{T_{02}}{T_{01}}-1}
$$

Now we have reached the point where the temperature could be determined from (14) if the efficiency is known and the power could then be determined from (13) if the mass flow is known. Models for these quantities will therefore be described in the following subsections.

\subsection{Compressor Flow Models}

Several models have been presented for compressor mass flows using either direct interpolation of the compressor map [21] or parameterized functions [5, 22-25], that vary in detail. An approach, that has successfully been used in the projects that this paper is based upon, is to use the dimensionless quantities in a central way in the models. The key idea is to describe the speed lines with the help of the 


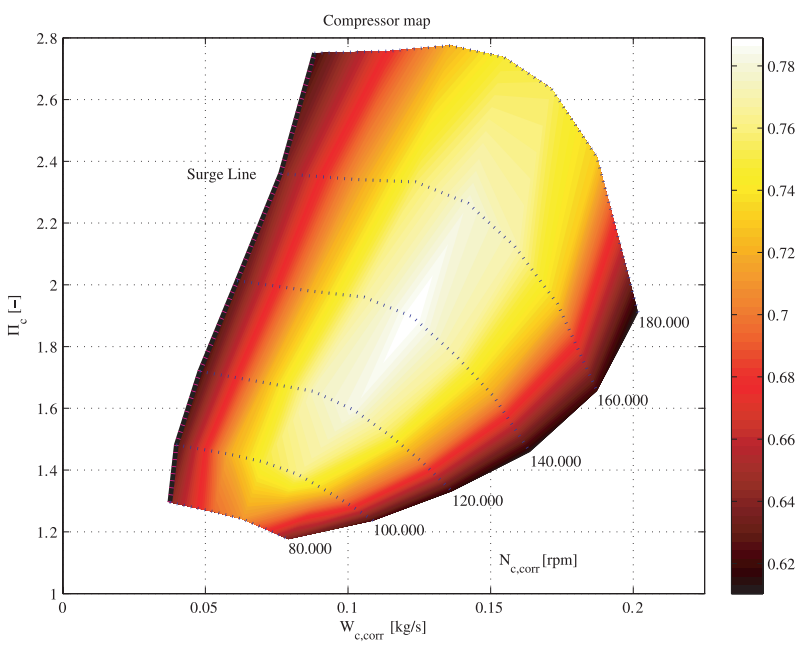

Figure 2

Compressor map showing the compressor efficiency map as a function of the pressure ratio $\Pi_{c}$ and corrected mass flow $W_{c, c o r r}$, with lines of constant corrected speed, and the surge line.

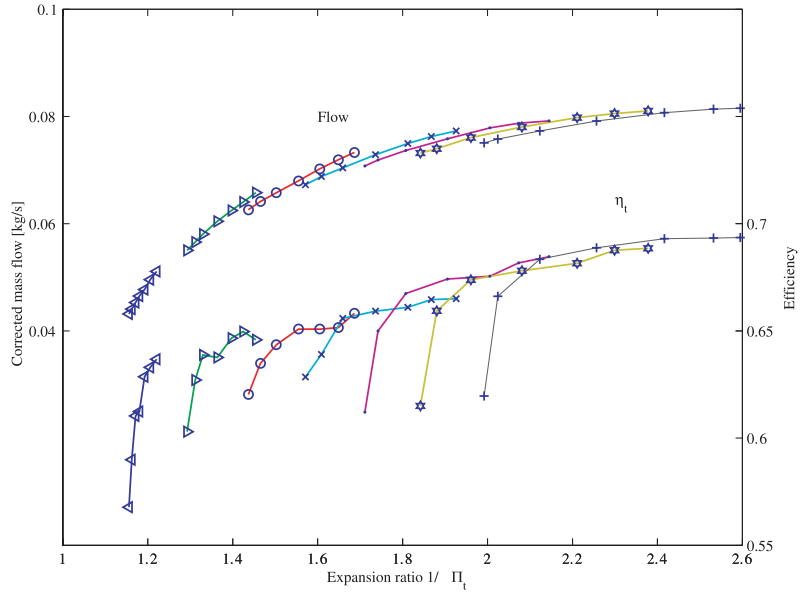

Figure 3

Turbine map showing the flow characteristic and the efficiency, for various lines of constant corrected speed. The $\mathrm{x}$-axis gives the expansion ratio $1 / \Pi_{t}$, the left $\mathrm{y}$-axis the corrected mass flow $W_{t, c o r r}$, and the right $\mathrm{y}$-axis gives the efficiency. dimensionless quantities shown in (7) to (10). By a proper selection of the model the parameters become easy to adjust and most importantly the model will have the ability to capture changes in environmental conditions since these effects are included in the dimensionless quantities.

\subsubsection{Parameterization with $\Psi$ and $\Phi$}

The main observation is that for a given compressor the function $f_{1}$, in (7), has its main dependence upon $\Phi$. This is shown for two compressors in Figure 4. The figure shows that all speed lines from the original map (left) are reduced to almost become one single curve in the $\phi, \Psi$ domain (right). Looking at the shape it is seen that it resembles one quarter of an ellipse. Therefore a straightforward approach is to describe this curve using an ellipsis, this approach has been followed in $[13,26]$. This is the first approximation and captures the most important features of the curve.

With this approach the mass flow is thus modeled using an ellipsis in $\Psi$ and $\Phi$, i.e.

$$
1=\left(\frac{\Phi}{a_{1}}\right)^{2}+\left(\frac{\Psi}{a_{2}}\right)^{2}
$$

Formulating the equations such that the compressor flow is described by pressure ratio, speed and compressor intake conditions gives the following calculation scheme

$$
\begin{aligned}
& \Psi=\frac{c_{p} T_{01}\left(\left(\frac{p_{02}}{p_{01}}\right)^{\frac{\gamma-1}{\gamma}}-1\right)}{\frac{1}{2} U_{2}^{2}} \\
& \Phi=a_{1} \sqrt{1-\left(\frac{\Psi}{a_{2}}\right)^{2}} \\
& W=\Phi \rho_{01} N D^{3}
\end{aligned}
$$

where $a_{1}$ and $a_{2}$ are tuning parameters. An important implementation detail is that if $\Psi$ gets bigger than $a_{2}$ then the solution becomes imaginary. This must be handled in simulation by monitoring the solution and limiting it to real values. The ellipsis is a good starting point that gives the basic shape and spread of the speed lines in the compressor map.

More complicated functions can be used to describe the relationship between $\Psi$ and $\Phi$. It is also possible to include the blade Mach number in the function to further enhance the model agreement and capture more dependencies. This is done in [22], where the same approach as above is applied but with the following relation between $\Phi$ and $\Psi$

$$
\begin{aligned}
\Phi & =\frac{k_{3} \Psi-k_{1}}{k_{2}+\Psi} \\
k_{i} & =k_{i 1}+k_{i 2} M a+k_{i 3} M a^{2}
\end{aligned}
$$

where $M a$ is the Mach number at the ring orifice of the compressor. $k_{i, j}$ are 9 tuning parameters that are fitted to the compressor map. Different variants of this approach have been reported, where the degrees of either the polynomials in the quotient (19) or (20) or both are changed. 

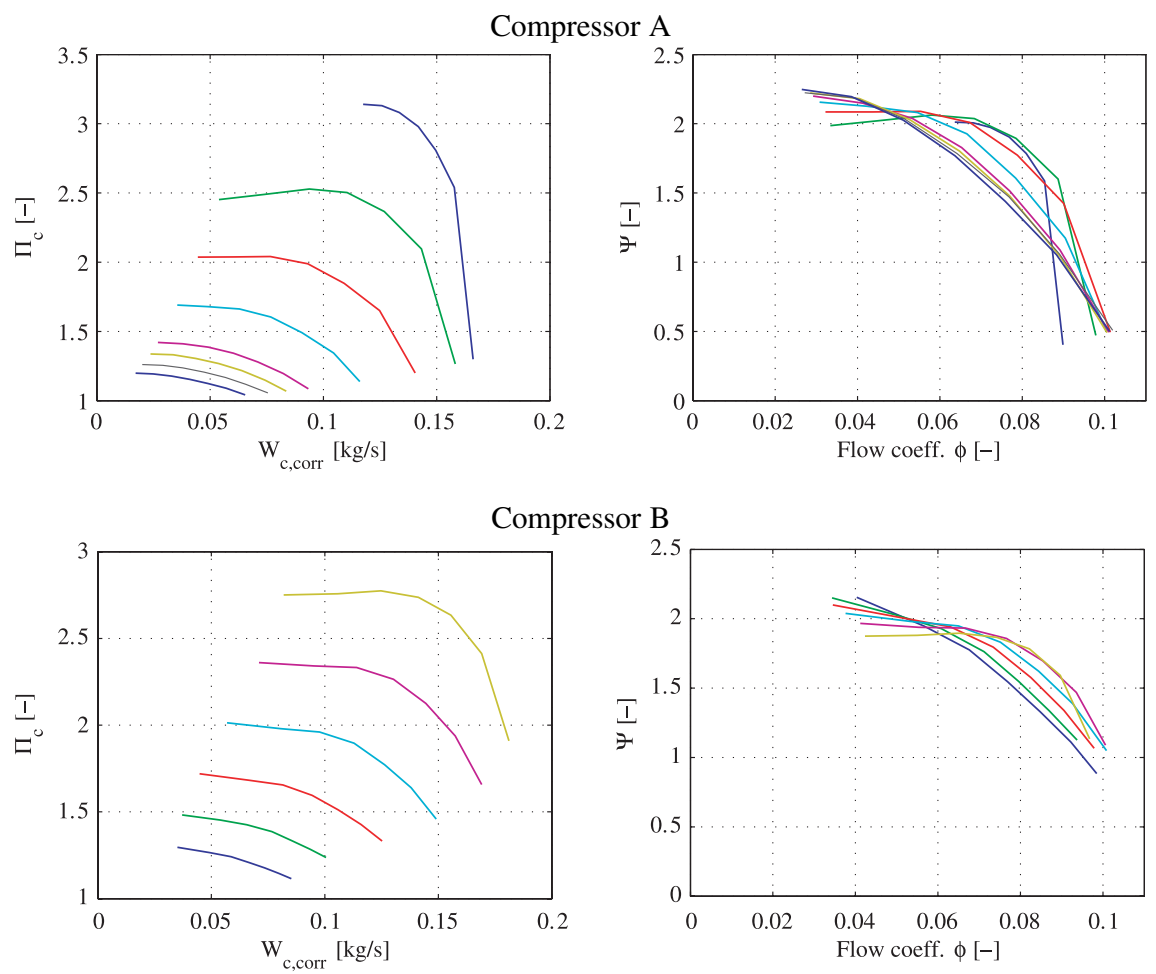

Figure 4

The speed lines are gathered together when studying the dimensionless numbers $\Psi$ and $\Phi$. Left: Speedlines in the original compressor map. Right: Transformation of the speedlines into the $\Psi, \Phi$ variables.

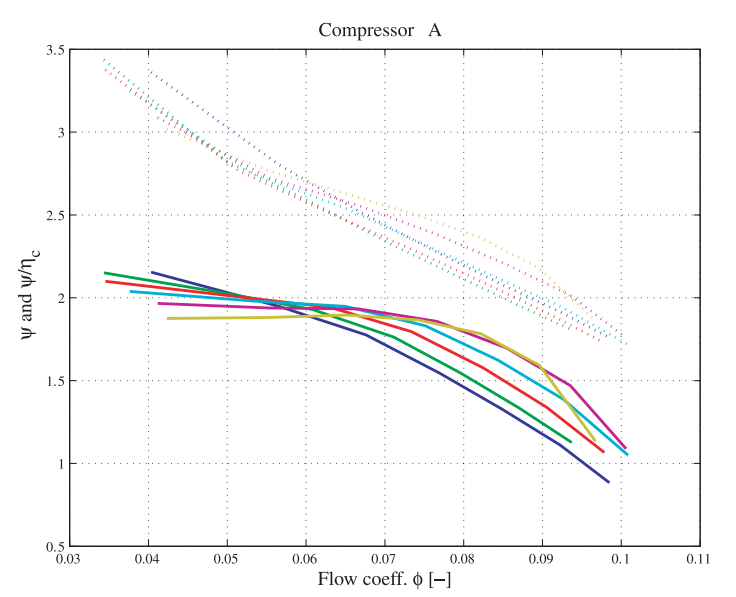

Figure 5

Relation between $\Phi, \Psi$ (solid curves) and $\Phi, \Psi / \eta_{c}$ (dashed curves) for compressor A.

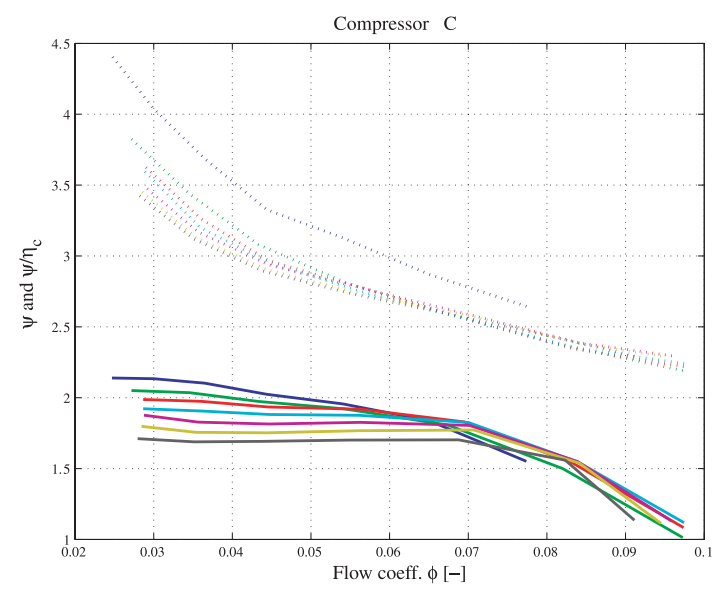

Figure 6

Relation between $\Phi, \Psi$ (solid curves) and $\Phi, \Psi / \eta_{c}$ (dashed curves) for compressor $\mathrm{C}$.

\subsubsection{Parameterization with $\phi$ and $\Psi / \eta_{c}$}

Looking further into the dimensionless numbers it can be seen that the following relation between them must hold $\hat{P}=\Phi \Psi / \eta_{c}$. In line with this it is possible to also study the relationship between $\Phi$ and $\Psi / \eta_{c}$, this is done in the inter- esting paper [25]. There data is presented from six different compressors that shows that the relation between the $\Phi$ and $\Psi / \eta_{c}$ variables follows a straight line

$$
\Phi=c_{0}+c_{1} \frac{\Psi}{\eta_{c}}
$$




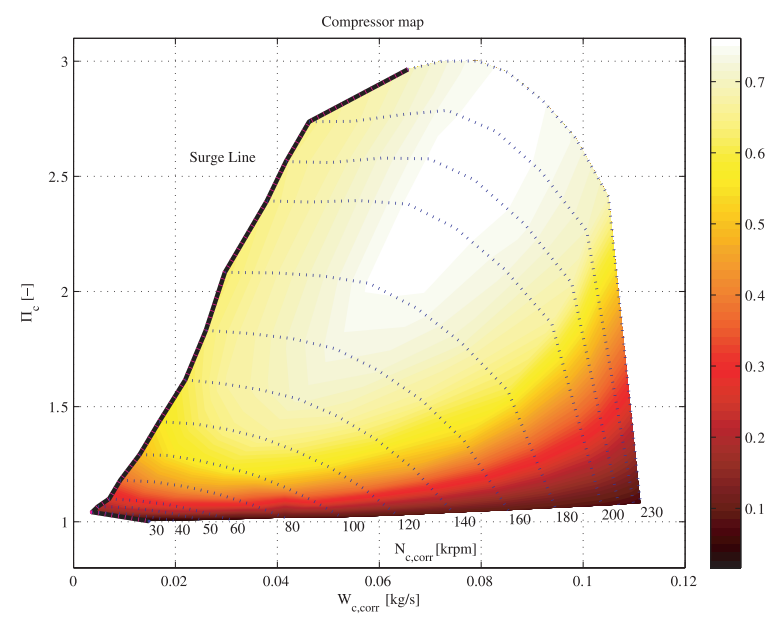

Figure 7

Compressor D has a map that covers the majority of the compressors operating region. The pressure ratio is measured down to values very close to unity, and there are many low speed lines included in the data. Note that the color map for the efficiency has a different scale compared to Figure 2.

This line also has nearly the same slope and constant for all compressors that were investigated in [25].

When applying this method to the five compressors here the same trends are seen, but there are four points worth to point out.

1. The trend between $\Phi$ and $\Psi$ is clearly concave, while trend between $\Phi$ and $\Psi / \eta_{c}$ is less curved but there is a slight convexity. See Figures 5 and 6.

2. The general trend for the slope of the line is the same but they differ slightly between each other. In particular Compressor C, Figure 6, has a significantly different slope compared to the others.

3. When the compressor is operating close to the design point (the region with high efficiency) the speed lines are well gathered. This conclusion does not seem to extrapolate. Two of the compressors, Compressor C and Compressor D, have been measured at speeds that are lower compared to the design speed. Compressor $\mathrm{C}$ have one speed line that clearly deviates from the general trend by lying slightly higher. Compressor D, has the biggest map and is shown in Figures 7 and 8, for this compressor the $\Psi / \eta_{c}$ lines are spread over a very large region, while the $\Psi \Phi$ still are close together. This illustrates the danger of drawing general conclusions from the traditional maps that only have measurements close to the design point.

4. This approach requires that the efficiency is also modeled from this $\eta_{c}\left(p_{01}, p_{02}, T_{01}, \omega_{t c}\right)$, which is difficult. This follows from the fact that these variables do not have the possibility to give a good description of the efficiency

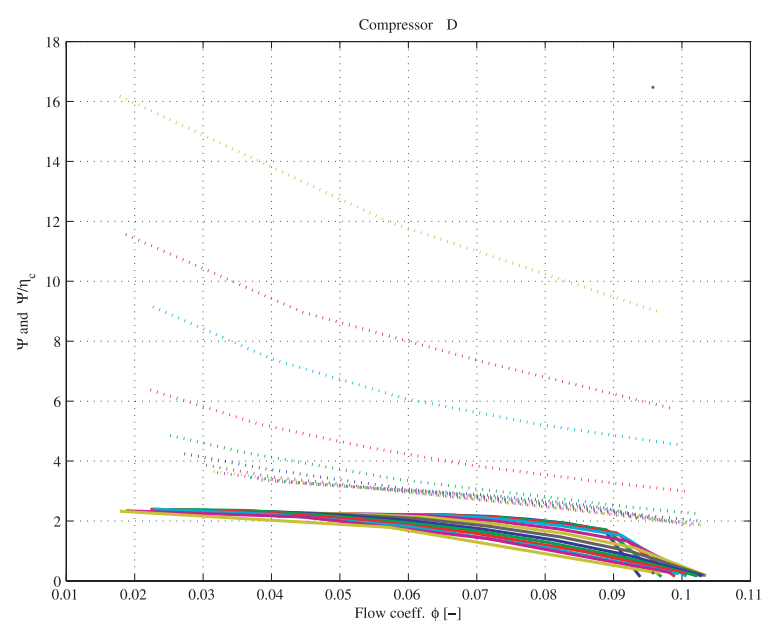

Figure 8

Relation between $\Phi, \Psi$ (solid curves) and $\Phi, \Psi / \eta_{c}$ (dashed curves) for compressor D.

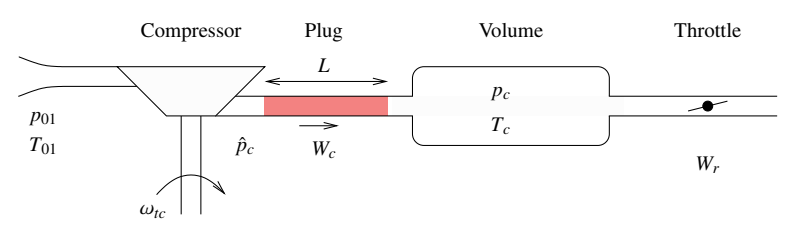

Figure 9

Components that constitute the ingredients in the basic Greitzer model for compressor surge.

close to the surge line, where the speed lines are almost horizontal.

\subsection{Surge Modeling}

One issue of general interest for the approaches above, where the compressor flow is described by a static function from pressure ratio, density and speed, is that the measured speed lines for higher speeds do not define a unique function from $\Pi_{c}$ to $W_{c}$. The approach above can thus not be used to describe all features of the compressor map, instead this can be done using following approach.

The compressor flow modeled is by including surge and the models are based on the standard Greitzer model [27] that describe the surge phenomenon see also [28,29]. This model has a time constant that is smaller than the normal filling and emptying dynamics included in the mean value engine models, and thus increases the bandwidth of the model and possibly also the computational demand.

The traditional Greitzer model is illustrated in Figure 9 and consists of four model components; pressure buildup in the compressor $\hat{p}_{c}$, acceleration of the mass that flows 

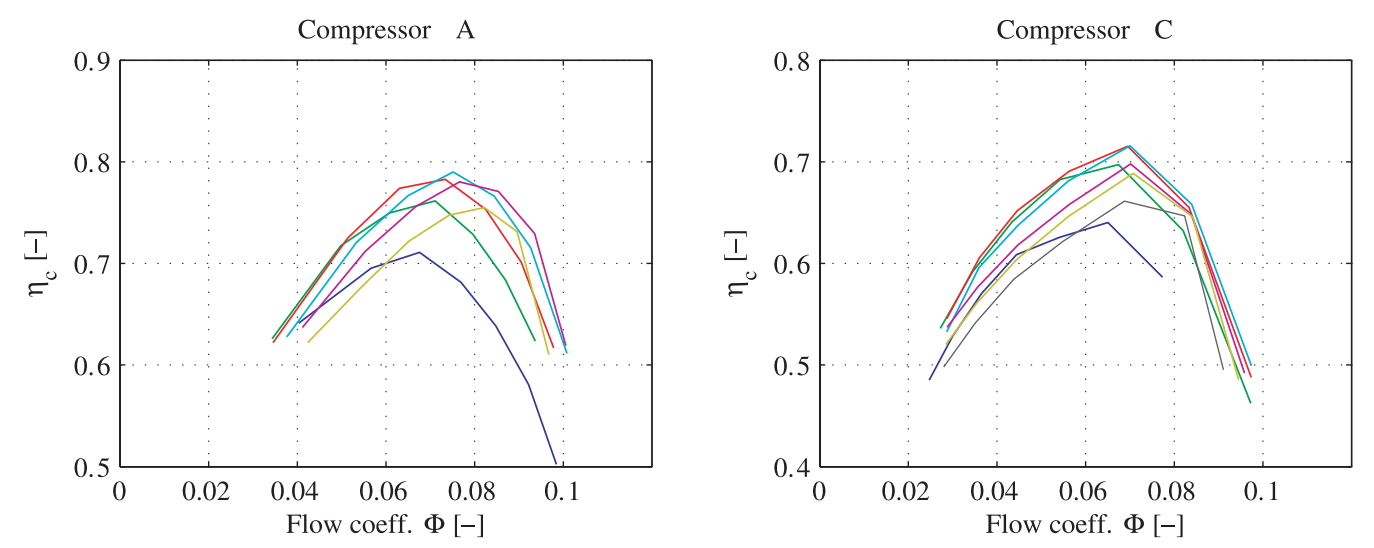

Figure 10

Compressor efficiency $\eta_{c}$ compared with flow parameter $\phi$, as it can be seen the flow parameter collects the speed lines close together.

through the compressor $W_{c}$, interaction with the pressures in the volumes before and after the compressor (which essentially is $p_{c}$ since $p_{01}$ is usually constant), and finally the throttle which has a strong influence on $p_{c}$. Adapting this approach by including only the pressure buildup in the compressor and acceleration of the mass flow $W_{c}$ gives a model that fits well into the general modeling framework, where the surrounding control volumes will provide the pressure for the compressor flow model.

Compressor pressure buildup depends on mass flow, compressor speed, and inlet conditions. It is very common to describe it using the dimensionless quantities $\Phi$ and $\Psi$, where the most simple models is a third order polynomial in $\Phi$ for $\Psi$. The models are tuned to have a local minimum at $\Phi=0$ and a maximum close to the surgeline, which occurs at $\Phi>0$. The calculation order is to first determine

$$
\Phi=\frac{W}{N D^{3}} \frac{R T_{01}}{p_{01}}
$$

then $\Psi$ is determined, using for example the third order polynomial

$$
\Psi=f(\Phi)
$$

and the compressor buildup is determined by solving for $p_{02}$

$$
\hat{p}_{c}=\left(\frac{1}{2} \frac{\Psi U_{2}^{2}}{c_{p} T_{01}}+1\right)^{\frac{\gamma}{\gamma-1}} p_{01}
$$

The second part of the model is the acceleration of mass in the compressor and surrounding tubes, where the mass is modeled as the gas captured in a pipe of diameter $D$ and length $L$ with a density determined by that in the control volume, i.e. $m=\rho_{c} L \frac{\pi D^{2}}{4}$. The force acting on the mass comes from the pressure difference between that generated by the compressor $\hat{p}_{c}$ and that in the volume $p_{c}$. Newton's second law now gives

$$
\rho_{c} L \frac{\pi D^{2}}{4} \frac{d V}{d t}=\frac{\pi D^{2}}{4}\left(\hat{p}_{c}-p_{c}\right)
$$

This equation is now rewritten to describe the acceleration of the mass flow, by noting that the flow velocity in a pipe is $V=\frac{W_{c}}{\rho_{c} \pi D^{2} / 4}$. Assuming that the density changes slower than the mass flow gives the following differential equation for the mass flow in the compressor

$$
\frac{d}{d t} W_{c}=\frac{\pi D^{2}}{4 L}\left(\hat{p}_{c}-p_{c}\right)
$$

\subsubsection{Including a Compressor Model with Surge}

A compressor model that includes surge can easily be incorporated as a component in a normal MVEM, since the calculation causality is the same as for normal compressor models and there is only one additional state (21). The causality in this model is opposite compared to the previous models, since the pressure ratio is here determined from the flow. The methodology with an ellipsis is applicable for both types of models $\left(W_{c}=f\left(\Pi_{c}, \omega_{t c}\right)\right.$ and $\left.\Pi_{c}=f\left(W_{c}, \omega_{t x}\right)\right)$. One issue of general interest is that the speed lines for higher speeds do not define a unique function, from $\Pi_{c}$ to $W_{c}$, and the approach above that allows the pressure buildup to be described freely as function of mass flow and rotational speed (or $\Phi$ ), can thus be used to describe all features of the compressor map. Furthermore, it also opens up the possibility to use the approach where the relation between $\Phi$ and $\Psi / \eta$ is utilized and where the efficiency can be described as a function of both the flow and the pressure ratio.

The drawback with the addition of a compressor surge model is that the total model for the system becomes stiff since the additional state (21) contributes with a fast mode 

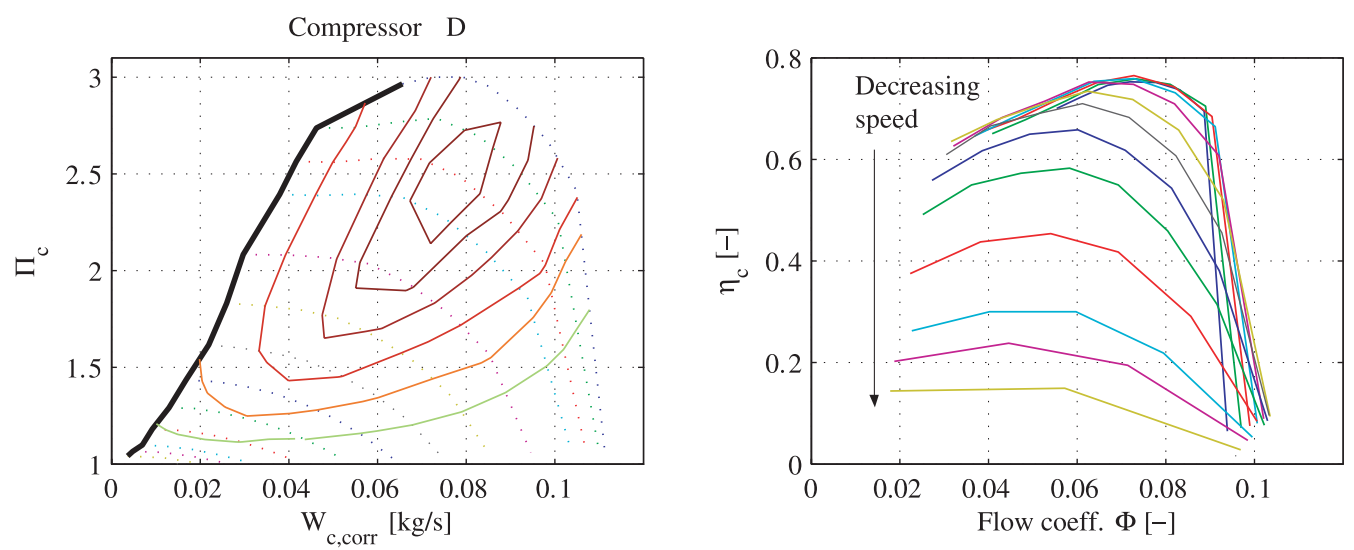

Figure 11

Compressor efficiency expressed in terms of the flow parameter $\phi$, note that efficiency approaches zero when the speed and flow is decreased.

while the complete turbocharger dynamics is considerably slower. Therefore some computational time is gained by omitting surge.

\subsubsection{Compressor Efficiency}

Compressor efficiency can also be modeled in many ways but the focus here is to concentrate on how the dimensionless quantities can be used for this modeling to give a compact description of the phenomenon. Looking at the compressor efficiency data, plotted in Figure 10, it is directly seen that the efficiency and flow parameter $\Phi$ are connected, and in particular that a function in $\Psi$ apparently gives a good approximation for $\eta_{c}$.

This indicates that the flow parameter can give a good description of the efficiency. A quadratic function in $\Phi$ could be used as a first approximation for the efficiency, when it is sufficient that the model describes the efficiency close to the design point. However, the compressor map is usually measured for speeds close to the compressor design point (i.e. the area where the compressor is designed to give best efficiency) when the speed drops the efficiency is lowered. This is shown in Figure 11 where the compressor performance is measured also for very low speeds and flows. The efficiency drop is visible both in the lower left corner in the compressor map and the scaled map. A more accurate model should therefore include both $\Phi$ and speed $\left(\right.$ or $\left.\Pi_{c}\right)$. Studying the compressor efficiency closer gives some more insight. Figure 12 shows a plot where the maximum position of the compressor efficiency has been found for each speed line and the result is plotted against the rotational speed. The figure shows that the position for the maximum in $\Phi$ depends linearly on the speed. The maximum efficiency as function of speed is plotted in Figure 13 and it can be seen that the efficiency is concave in the speed
This can now be utilized in the modeling of the compressor. Since the efficiency is concave in both $\Phi$ and $N_{c, c o r r}$ one option is to model the compressor efficiency using a quadratic form in $\Phi$ and $N_{c, c o r r}$.

$$
\begin{aligned}
\eta_{c}\left(\Phi, N_{c, \text { corr }}\right) & =\eta_{c, \text { max }}-\chi^{T} Q_{\eta} \chi \quad \text { where } Q_{\eta} \in \mathfrak{R}^{2 \times 2} \\
\chi & =\left[\begin{array}{c}
\Phi-\Phi_{\max } \\
N_{c, \text { corr }}-N_{\text {corr }, \text { max }}
\end{array}\right]
\end{aligned}
$$

Here $\eta_{c, \text { max }}, \Phi_{\text {max }}$, and $N_{\text {corr,max }}$ are tuning parameters together with the elements in the matrix $Q$. Note that $Q_{\eta}$ must be symmetric and positive definite in order to give a quadratic form with a maximum. This efficiency model makes the efficiency symmetric in $\Phi$ and $N$.

If the skewness of $\eta_{c}$ in $\Phi$ is important it possible to model the efficiency using a product of efficiencies

$$
\eta_{c}\left(\Phi, N_{c, c o r r}\right)=\eta_{c, \Phi}\left(\Phi-\left(c_{0}-c_{1} N_{c, c o r r}\right)\right) \cdot \eta_{c, N}\left(N_{c, c o r r}\right)
$$

Here the skewness of the efficiency with respect to $\Phi$ can be captured by using for example a third order polynomial for $\eta_{c, \Phi}\left(\Phi-\left(c_{0}-c_{1} N_{c, c o r r}\right)\right)$. The first part of the speed dependence, shown in Figure 12, is included in $\eta_{c, \Phi}$ and the concave behavior, Figure 13, can then be modeled using a second or higher order polynomial, for example

$$
\eta_{c, N}\left(N_{c, c o r r}\right)=1-c_{N}\left(N_{c, c o r r}-N_{\max }\right)^{2}
$$

\section{TURBINE MODELS}

The technique and requirements on turbine modeling are the same as for the compressor. Firstly, to fit into the frame work the turbine model has to deliver a mass flow and turbine outlet temperature. Secondly, the turbine must also provide the turbine power that drives the compressor. 


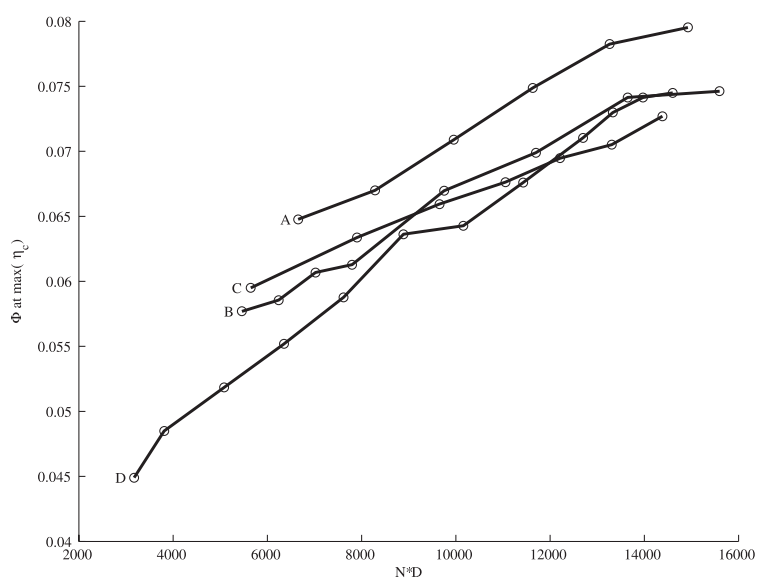

Figure 12

The flow coefficient where the maximum efficiency occur as function of $N D$. The dependence is linear.

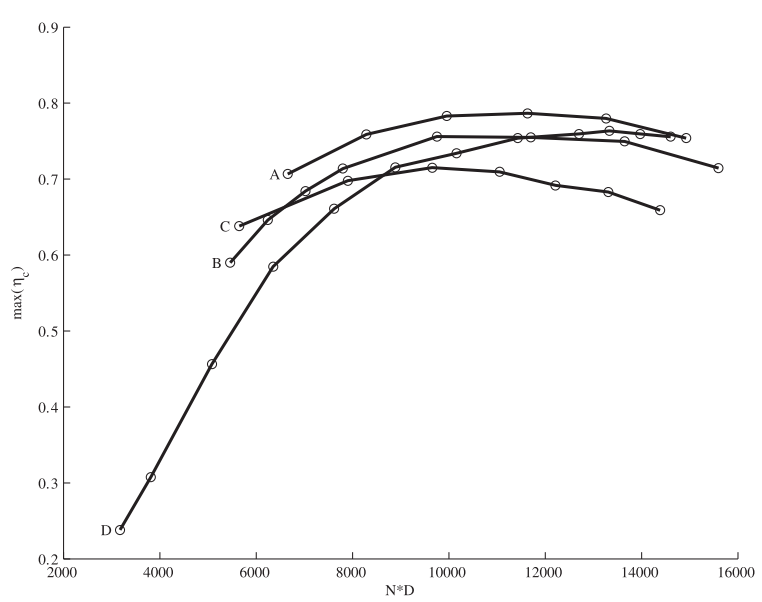

Figure 13

The maximum efficiency as function of compressor speed for four different compressors. The function is concave.

The equations are

$$
\begin{aligned}
P_{t} & =W_{t} c_{p, t}\left(T_{03}-T_{04}\right) \\
\eta_{t} & =\frac{1-\frac{T_{04}}{T_{03}}}{1-\left(\frac{p_{04}}{p_{03}}\right)^{\frac{\gamma-1}{\gamma}}}
\end{aligned}
$$

As for the compressor this thus requires that turbine flow and efficiency models have to be developed.

\subsection{Turbine Efficiency}

Turbine efficiency models are conveniently expressed as quadratic functions in blade speed ratio BSR as was sug-

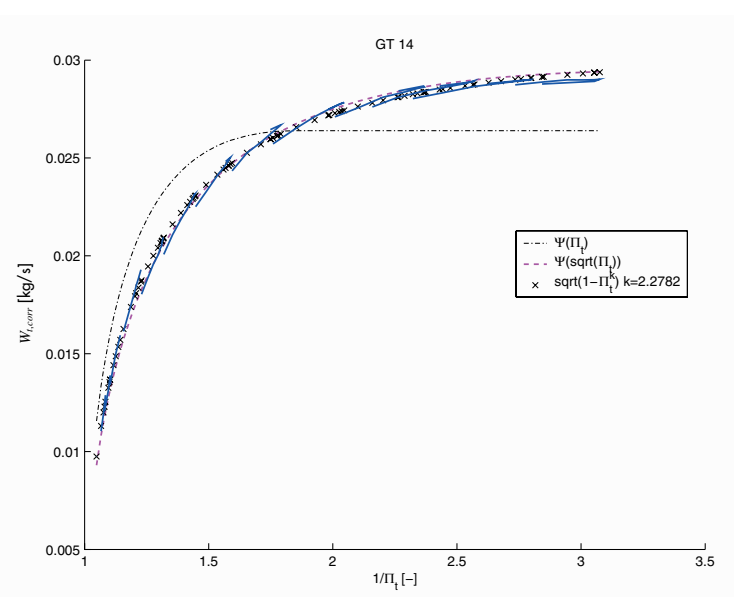

Figure 14

Evaluation of the standard throttle models for one turbine, the solid line segments show speed lines in the measured data. Which shows that the standard throttle model gives choking condition that occur for too low pressure ratios.

gested in [30]. BSR is defined as

$$
B S R=\frac{\omega_{t} r_{t}}{\sqrt{2 c_{p} T_{03}\left(1-\Pi_{t}^{\frac{\gamma e-1}{\gamma_{e}}}\right)}}
$$

The most simple form of an efficiency model is thus

$$
\eta_{t}=\eta_{t, \max } \cdot\left(1-c_{t} \cdot\left(B S R-B S R_{\max }\right)^{2}\right)
$$

Here it is important to remember that in most cases the manufacturer data for turbine efficiency includes the mechanical efficiency of the turbo charger shaft. This is a consequence from that the turbine performance is usually determined together with a compressor and the procedure utilizes the compressors power consumption to determine the turbine efficiency. Furthermore sometimes also a pulse compensation factor must be added to get a good description of the operation of the turbine and turbocharger on a real engine.

\subsection{Turbine Mass Flow}

The goal with the turbine mass flow model is to describe the flow characteristic seen in Figure 3. Two very simple mass flow models have been used that give a good description of the turbine performance.

\subsubsection{The Standard Restriction Model}

The first one has its roots in the standard model for compressible flow through a restriction (3). It is usually applied to model the turbine flow: 


$$
\begin{aligned}
\Pi_{t}^{*} & =\max \left(\Pi_{t},\left(\frac{2}{\gamma+1}\right)^{\frac{\gamma}{\gamma-1}}\right) \\
W_{t} & =\frac{p_{03}}{\sqrt{R T_{03}}} \cdot A_{e f f} \cdot \Psi\left(\Pi_{t}^{*}\right) \\
\Psi\left(\Pi_{t}^{*}\right) & =\sqrt{\frac{2 \gamma}{\gamma-1}\left(\Pi_{t}^{*} \frac{2}{\gamma}-\Pi_{t}^{*} \frac{\gamma+1}{\gamma}\right)}
\end{aligned}
$$

This model does not describe the physics of the flow in a turbine and many authors have therefore augmented that model to fit data, see e.g. [22, 24,31]. Applying the standard restriction to a turbine flow, where the effective area is adjusted to give the best fit, gives a model that reaches choking conditions too early, see the dash dotted line in Figure 14.

One parameter in the model is $\gamma$ which some authors have argued that it should be changed since the flow is not isentropic. If $\gamma$ is freely adjusted so that the model gives a good fit to measured data. For the data in Figure 14 it had to be adjusted to $\gamma=4$. This is clearly unphysical, since $\gamma<1.4$ for exhaust gases which makes this adjustment less interesting as a physical model for the turbine flow. Similar arguments for why the turbine can not be modeled directly as standard restriction are pointed out in [24]. There are other proposals for overcoming this that introduce a pressure dependent term in the $\Psi$-function, $W_{t, \text { corr }}=A \cdot f\left(\Pi_{t}\right) \cdot \Psi\left(\Pi_{t}\right)$ which has the possibility to compensate for the errors introduced by the restriction model.

The standard restriction models might be justified when considering reaction turbines that are configured with a throat in series with an impeller. The throat accelerates the fluid and then the impeller decelerates the flow while it is extracting work from the kinetic energy. This limits the flow to sonic conditions at the nozzle exit, and for such a turbine the throttle model may suffice. In a radial turbine the gases are also expanding in the rotor and this is characterized by the characteristic number, $\mathrm{RN}$, degree of reaction. During the expansion in the turbine, work is also done by the fluid which reduces the kinetic energy and thus enhances the possibilities, of the turbine, to increase the mass flow when the total expansion ratio over the turbine is decreased without hitting the critical velocity of sound. According to [18] it is difficult to design a turbine with a degree of reaction far from $R N=0.5$, which shows that it is possible to increase the flow for expansion ratios up to the order of double the choking limit for a standard throttle.

\subsubsection{Modification of the Restriction Model}

If we rely upon the statement that $R N=0.5$ then half the expansion is in the stator and the other half in the rotor this then divides the total pressure ratio over the turbine into the following two equal pressure ratios

$$
\Pi_{t}=\underbrace{\sqrt{\Pi_{t}}}_{\text {stator }} \cdot \underbrace{\sqrt{\Pi_{t}}}_{\text {rotor }}
$$

then choking will occur in the stator (or rotor) only when the critical pressure ratio is reached in one of the stages. Based upon this the turbine flow is modeled using the compressible flow for a restriction with

$$
\Psi\left(\sqrt{\Pi_{t}}\right) \text { inserted into (24) }
$$

this model gives good agreement with the measured data, see the dashed line in Figure 14.

\subsubsection{A Simple Black Box Model}

There are simple models that give good fit to measured data one is (from [9])

$$
W_{t, c o r r}=c_{0} \sqrt{1-\Pi}
$$

This model is not sufficiently flexible for describing the flow, and a slightly more flexible model is one with a free exponent added to the pressure ratio

$$
W_{t, c o r r}=c_{0} \sqrt{1-\Pi^{k}}
$$

Here the exponent $k$ is also a tuning parameter that has been found to lie around $k=2$. The last model is validated in Figure 14 and it is shown that it gives a good agreement with $k=2.27$.

\subsection{Variable Geometry Turbines (VGT)}

When considering a VGT the same approach as above can be used and the effective area in (25) and (24) is used to describe the function of the VGT actuator. The model (26) can also be used and then the constant $c_{0}$ is replaced by a function of the VNT actuator, $c_{0}\left(u_{v n t}\right)$.

\section{APPLICATIONS}

The modeling methodology and the component models have been utilized in several projects and some of these will be summarized here.

\subsection{Air/Fuel Ratio Control}

The methodology is applied and used in [13,32-34] for transient air/fuel ratio control. The model is implemented in Simulink and the top level diagram is shown in Figure 15.

\subsubsection{The Model}

A component based modeling approach has been applied with control volumes in series with restrictions and flow 


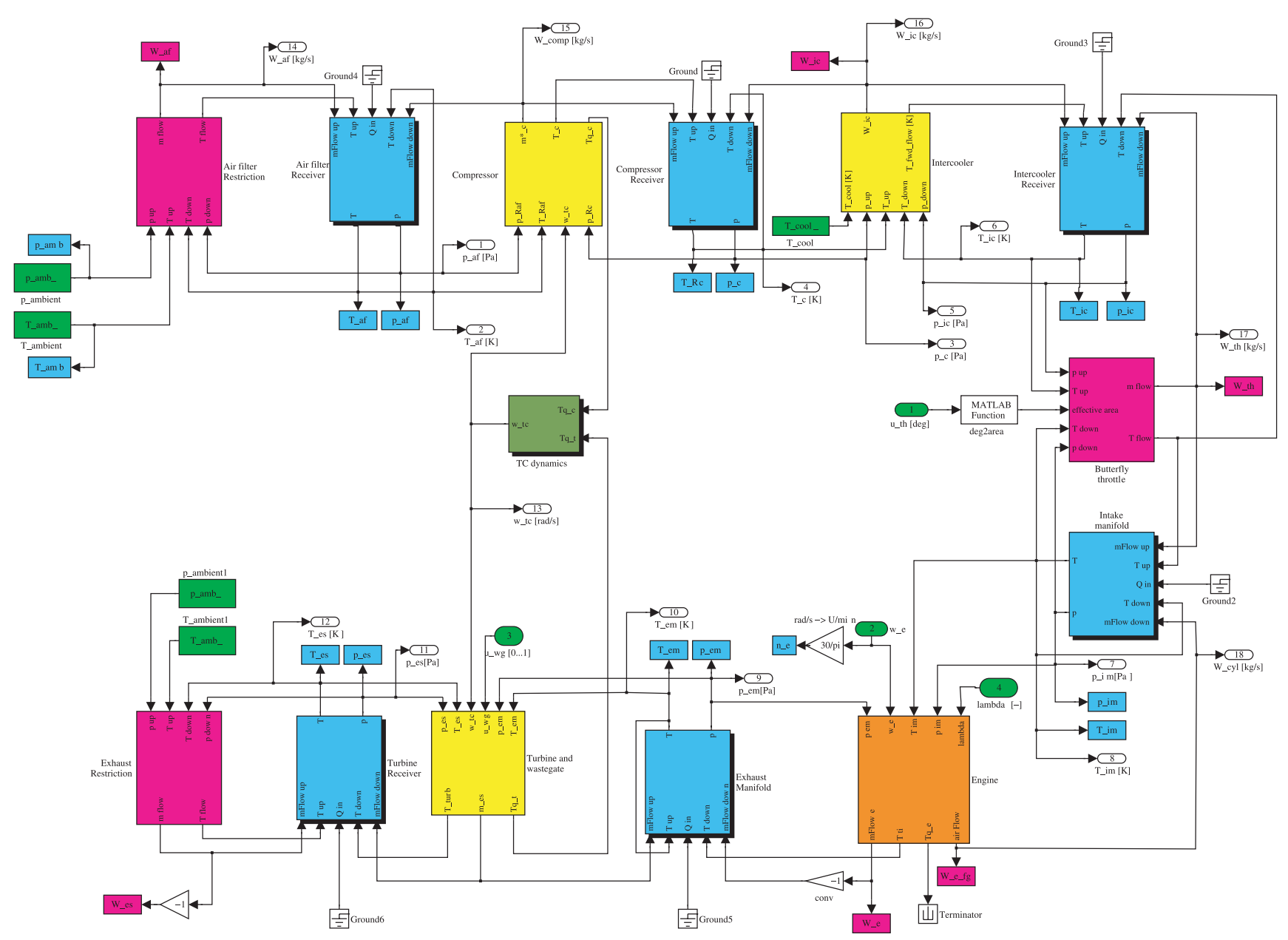

Figure 15

Simulink diagram of a turbocharged SI engine. The engine is modeled in a component based fashion with control volumes in series with restrictions or flow. Control volumes are named receivers in the diagram.

generators (compressor, turbine, and engine). The model consists of:

- Six control volumes for the tubes and other volumes present in the engine, all modeled by (1). The components are volume between air filter-compressor, compressor-intercooler, intercooler-throttle, intake manifold, exhaust manifold, and finally exhaust pipe between turbine and catalyst.

- Three restrictions for turbulent incompressible flow (2). These components are air filter, intercooler, and a lumped model for the pressure drop in the exhaust system like catalyst and muffler.

- Two compressible isentropic restrictions, (3), one for the throttle and one for the wastegate (included in the turbine).
- The compressor model is based on the dimensionless numbers, for the flow and the efficiency is modeled in the approach based on (22).

- The intercooler temperature drop is modeled using a regression polynomial similar to that in [9].

- The turbine is modeled using (26) for the flow and (23) for the efficiency.

- The engine flow is parameterized using the volumetric efficiency $\eta_{v o l}$.

\subsubsection{Applications}

In this project it is used as the basis for an air path observer for a turbo charged SI engine. The resulting model has thirteen states and in [34] it is shown to be structurally observable from any arbitrary sensor signal. The model is 


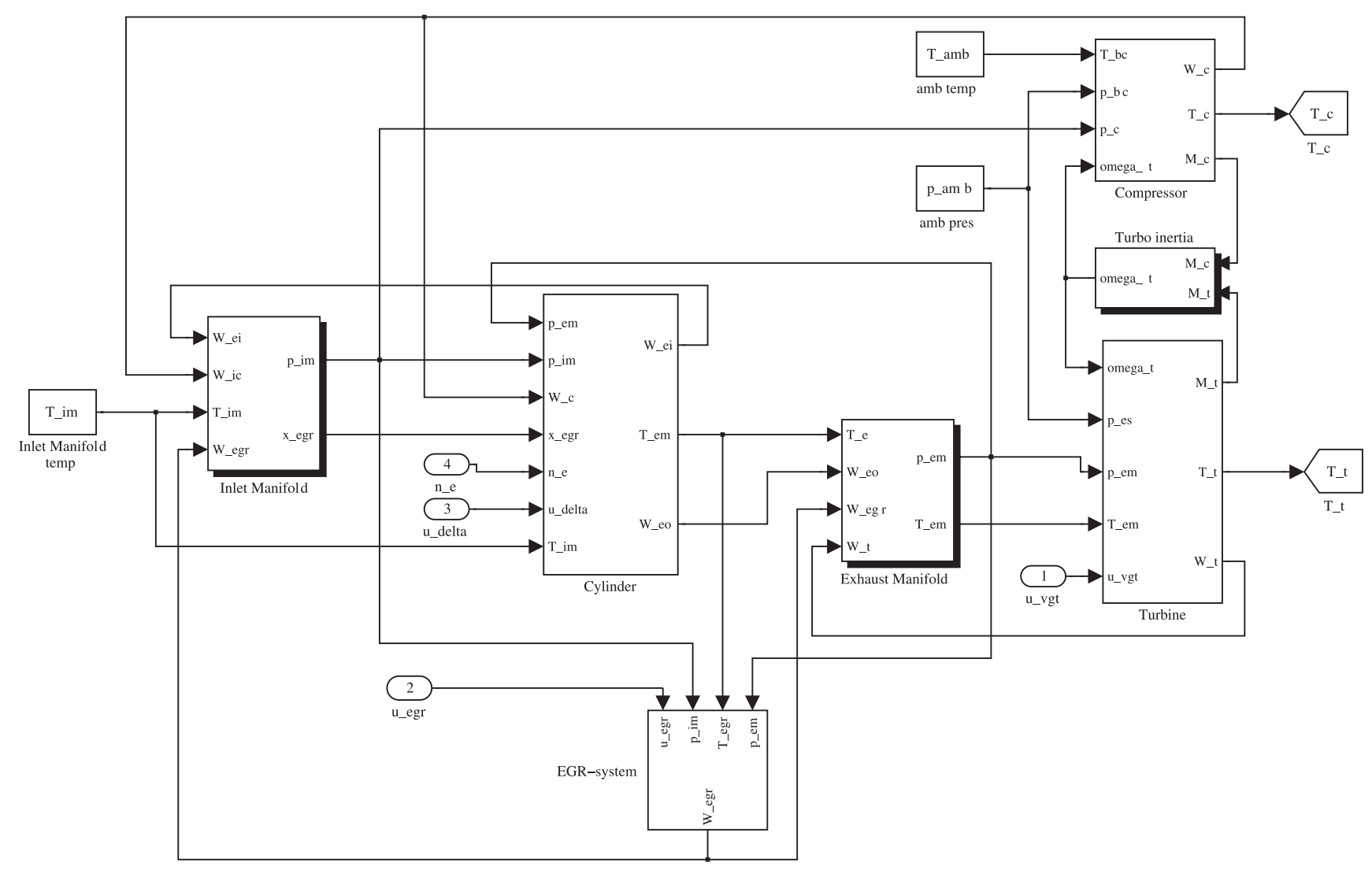

Figure 16

A model for a turbocharged diesel engine with VGT and EGR that is implemented in Simulink.

then used in a non linear observer that utilizes gain switching strategy for estimating the amount of air that enters the cylinders [32]. A methodology for determining the observer feedback gains, based on a Kalman filter, for this system is developed. Finally the model is used in a nonlinear observer, and it is run in real time for transient air/fuel ratio control [33]. Matlab, Simulink and Real Time Workshop were used to transfer the Simulink implementation of the model and observer to the real time system.

\subsection{EGR/VGT Control}

A structure for EGR and VGT control is developed and investigated using a model that have been developed using the methodology.

\subsubsection{The Model}

The concluding example is a model implemented in Simulink for a turbocharged diesel engine with VGT and EGR. The Simulink implementation of the model is given in Figure 16. The DI model follows the same modeling principles as the gasoline engine above and also includes similar model components as the SI engine.

To highlight a few points:

- The compressor model is the same as for the SI Engine above, it is based upon the dimensionless numbers, for the flow and (22).

- The turbine is modeled using (26) for the flow and (23) for the efficiency.

- The engine flow is based on the volumetric efficiency $\eta_{v o l}$.

- The EGR cooler and intercooler are modeled as perfect coolers so that the outlet temperatures are the same as the coolant media.

\subsubsection{Applications}

The model is used to develop control strategy for control of the EGR and VGT. A system analysis based upon both engine measurements and the model shows that there are several important issues that must be handled by the controller. A structure is then developed that can handle these 
issues $[35,36]$, the model is used to tune the controller parameters before they are applied in an engine test.

\section{CONCLUSIONS}

A component based modeling methodology for mean value engine models has been presented. Several component models have been summarized and described but also a set of new models have been developed and described. The new models describe compressor flow, compressor efficiency and turbine flow. The new models have compact representations, are easy to implement, and are simple to tune to measurement data. Finally two applications are described where the modeling methodology and the components are used.

\section{ACKNOWLEDGEMENTS}

Much of the knowledge summarized here has been developed during joint work on modeling and control of turbocharged engines and the following are worth a special mention: Per Andersson, GM Powertrain, Sweden; Johan Wahlström, LiU, Sweden; and Simon Frei, ETH, Switzerland.

\section{REFERENCES}

1 L. Guzzella, U. Wenger, and R. Martin (2000) IC-engine Downsizing and Pressure-Wave Supercharging for Fuel Economy. SAE Technical Paper 2000-01-1019.

2 P. Soltic (2000) Part-Load Optimized SI Engine Systems. PhD Thesis, Swiss Federal Institute of Technology, Zürich.

3 D. Petitjean, L. Bernardini, Ch. Middlemass, S.M. Shahed, and R.G. Hurley (2004) Advanced gasoline engine turbocharging technology for fuel economy improvements. SAE Technical Paper 2004-01-0988.

4 M.J. van Nieuwstadt, I.V. Kolmanovsky, P.E. Moraal, A. Stefanopoulou, and M. Jankovic (2000) EGR VGT control schemes: Experimental comparison for a high-speed diesel engine. IEEE Cont. Syst. Mag., 20, 63-79.

5 L. Guzzella and A. Amstuz (1998) Control of diesel engines. IEEE Contr. Syst. Mag., 18, 53-71.

6 M. Jankovic, M. Jankovic, and I. Kolmanovsky (2000) Constructive lyapunov control design for turbocharged diesel engines. IEEE T. Contr. Syst. T., 8, 288-299.

7 M. Nyberg (2002) Model-based diagnosis of an automotive engine using several types of fault models. IEEE T. Contr. Syst. T., 10, 679-689.

8 K. Yong-Wha, G. Rizzoni, and V. Utkin (1998) Automotive engine diagnosis and control via nonlinear estimation. IEEE Contr. Syst. Mag., 18, 84-99.

9 L. Eriksson, L. Nielsen, J. Brugård, J. Bergström, F. Pettersson, and P. Andersson (2002) Modeling and simulation of a turbo charged SI engine. Annu. Rev. Control, 26, 129-137.
10 E. Hendricks (2001) Isothermal $v s$. adiabatic mean value SI engine models. In 3rd IFAC Workshop, Advances in Automotive Control, Preprints, Karlsruhe, Germany, 373-378.

11 B. Massey (1998) Mechanics of Fluids. Stanley Thornes, 7th edition.

12 A. Ellman and R. Piché (1999) A two regime orifice flow formula for numerical simulation. J. Dyn. Syst., 121, 721-724.

13 P. Andersson (2005) Air Charge Estimation in Turbocharged Spark Ignition Engines. PhD Thesis, Linköpings Universitet.

14 J.B. Heywood (1988) Internal Combustion Engine Fundamentals. McGraw-Hill series in mechanical engineering. McGrawHill.

15 P. Andersson and L. Eriksson (2004) Cylinder air charge estimator in turbocharged SI-engines. In SAE Technical Paper 2004-01-1366.

16 L. Eriksson (2002) Mean value models for exhaust system temperatures. SAE Transactions, J. Engines, 2002-01-0374, 111.

17 J. Wahlström and L. Eriksson (2006) Modeling of a diesel engine with VGT and EGR including oxygen mass fraction. Technical report, Vehicular Systems, Department of Electrical Engineering, Linköping University.

18 N. Watson and M.S. Janota (1982) Turbocharging the Internal Combustion Engine. The Macmillan Press. ISBN 0-33324290-4.

19 R.I. Lewis (1996) Turbomachinery Performance Analysis. Arnold.

20 S.L. Dixon (1998) Fluid Mechanics and Thermodynamics of Turbomachinery. Butterworth-Heinemann, 4th edition.

21 M. Kao and J.J. Moskwa (1995) Turbocharged diesel engine modeling for nonlinear engine control and state estimation. $J$. Dyn. Syst. - T. ASME, 117, 20-30.

22 J.P. Jensen, A.F. Kristensen, S.C. Sorenson, N. Houbak, and E. Hendricks (1991) Mean value modeling of a small turbocharged diesel engine. SAE Technical Paper 910070.

23 M. Müller, E. Hendricks, and S.C. Sorenson (1998) Mean Value Modelling of Turbocharged Spark Ignition Engines. SAE SP-1330 Modeling of SI and Diesel Engines, (SAE Technical Paper 980784), 125-145.

24 P. Moraal and I. Kolmanovsky (1999) Turbocharger Modeling for Automotive Control Applications. SAE Technical Paper 1999-01-0908, 309-322.

25 S.C. Sorenson, E. Hendrick, S. Magnusson, and A. Bertelsen (2005) Compact and accurate turbocharger modelling for engine control. In Electroni Engine Controls 2005 (SP-1975), SAE Technical Paper 2005-01-1942.

26 J. Wahlström and L. Eriksson (2004) Modeling of a diesel engine with VGT and EGR. Technical report, Vehicular Systems, Department of Electrical Engineering, Linköping University.

27 E.M. Greitzer (1981) The stability of pumping systems - the 1980 freeman scholar lecture. J. Fluid Eng., 103, 193-242.

28 J.T. Gravdahl and O. Egeland (1999) Centrifugal compressor surge and speed control. IEEE T. Contr. Syst. T., 7, 567-579. 
29 M. Ammann, N.P. Fekete, A. Amstutz, and L. Guzzella (2001) Control-oriented modeling of a turbocharged common-rail diesel engine. In Proceedings from the 3rd. Int. Conference on Control and Diagnostics in Automotive Applications (CD Auto 01), Sestri Levante.

30 N. Watson (1981) Transient performance simulation and analysis of turbocharged diesel engines. In SAE Technical Paper 810338 .

31 L. Eriksson, L. Nielsen, J. Brugård, J. Bergström, F. Pettersson, and P. Andersson (2001) Modeling and simulation of a turbo charged SI engine. In 3rd IFAC Workshop "Advances in Automotive Control', Preprints, 379-387, Karlsruhe, Germany, 2001. Elsevier Science.

32 P. Andersson and L. Eriksson (2004) Mean-value observer for a turbocharged SI-engine. In IFAC Symposium on Advances in Automotive Control, University of Salerno, Italy, April 19-23, 146-151.
33 P. Andersson and L. Eriksson (2005) Observer based feedforward air-fuel control of turbocharged SI-engines. IFAC World Congress, Prague, Czech Republic.

34 P. Andersson, E. Frisk, and L. Eriksson (2005) Sensor selection for observer feedback in turbocharged spark ignited engines. IFAC World Congress, Prague, Czech Republic.

35 J. Wahlström, L. Eriksson, L. Nielsen, and M. Pettersson (2005) PID controllers and their tuning for EGR and VGT control in diesel engines. IFAC World Congress, Prague, Czech Republic.

36 J. Wahlström (2006) Control of EGR and VGT for emission control and pumping work minimization in Diesel engines. Licentiate Thesis, Linköping University.

Final manuscript received in December 2006 